ORIGINAL ARTICLE

\title{
Unanswered questions in contraceptive management: What do the experts do?
}

Catherine Brooker, FRACGP, DFFP, General Practitioner, Perth, Australia; John Guillebaud, FRCSE, FRCOG, Emeritus Professor of Family Planning and Reproductive Health, Department of Obstetrics and Gynaecology, University College London, London, UK

Correspondence: Dr Catherine Brooker.E-mail: cathybrooker@hotmail.com

(Accepted 28 May 2004)

Journal of Family Planning and Reproductive Health Care 2004; 30(4): 229-235

\begin{abstract}
Context Several areas exist in the practice of contraception where evidence for practice is deficient, yet clinical decisions need to be made.

Objectives The aim of the study was to find the practice habits of lead practitioners in the area of contraception in specific clinical scenarios where the published evidence is inadequate to provide clear guidance to clinicians. Results can provide 'Level $V$ ' evidence for practice for the 'nonexpert' practitioner.

Design Descriptive study.

Participants The study was conducted as a postal questionnaire mailed to the 205 lead practitioners whose contact details were known through the Society of Consultants in Reproductive Health (hereafter referred to as 'consultants') working in reproductive health in the National Health Service.

Results A total of 138 consultants returned completed questionnaires $(67 \%$ response rate). Important result included $100 \%$ of respondents being prepared to prescribe progestogen-only emergency contraception more than once in a cycle (contrary to product labelling) and $71 \%$ recommending two tablets daily of the progestogen-only pill for women of high body mass.

Conclusions Some questions had responses that showed clear majorities, providing a clear guide to practice, while other areas remain doubtful. Comments from respondents indicated great interest in all areas covered and a desire for consensus on many of the issues. Certainly the licensing and the advice from pharmaceutical companies is conservative, and in many scenarios a majority of consultants indicated that in order to serve the best interests of their clients they feel constrained to practise outside the Summary of Product Characteristics.
\end{abstract}

\section{Introduction}

Many areas exist in the clinical practice of contraception where evidence for practice is lacking. Despite this, practitioners are forced to give advice to their patients/clients regarding use. In many areas clinical studies may be unfeasible due to very low failure rates of methods (hence necessitating huge numbers for adequate power) or unethical risks of pregnancy. Moreover, randomised controlled trials are usually impractical because choice of, and continuation with, any contraceptive are both crucially dependent on individualised counselling. The kind of woman who will accept randomisation is therefore liable to be very unrepresentative of the whole population group.

Some of the answers to dilemmas of clinical practice may be provisionally surmised from physiological knowledge and biological plausibility. Unfortunately, at times this is difficult to work out and can seem contradictory. 'Absence of evidence' of an effect (whether affecting contraception, or an adverse or a beneficial side effect) is not the same thing as 'evidence of absence'. The lawyers who advise drug companies and regulatory agencies are often unprepared to permit any guidance to practitioners. Nevertheless, the latter have to make a decision in the best interests of, and in consultation with, the client sitting before them - at time present, one way or another, before the evidence being called for exists

The terms 'unlicensed' and 'named patient' prescribing are used in this article to describe the common practice of clinicians. Whenever licensing procedures have not yet caught up with what is widely considered the best evidence-based practice, such use is quite often necessary for optimal contraceptive care. It is legitimate, medically and legally, provided certain criteria are observed. 1,2

This paper provides information about the practices of specialists in some difficult situations, but it should not be read as necessarily supporting these practices, whether they are those of a majority or a significant minority of those surveyed. Health care professionals must as always take ultimate responsibility for the application of clinical advice to the specific circumstances that apply to their patient.

\section{Objectives}

This study aimed, through a questionnaire, to find and present the views and practices of lead practitioners in the field. In the absence of Levels I-IV evidence (Table 1$)^{3}$ in the selected areas of contraceptive management, this study provides Level V evidence. Thus it could give the "nonexpert practitioner' (i.e. general practitioners and family planning nurses and doctors) some support in these difficult areas of practice.

\section{Setting/participants}

The study was performed within the National Health Service in the UK, respondents being based all over the country. The North Thames Local Research Ethics Committee Chair approved the study.

The 205 lead consultants and those senior clinical medical officers in reproductive health who act as the clinical leads for a locality were identified through the

\begin{tabular}{ll} 
Table 1 Levels of evidence for evidence-based medicine & 1 \\
\hline Level of evidence & $\begin{array}{l}\text { Level based on: } \\
\text { Systematic reviews of randomised controlled trials } \\
\text { (RCTs) or individual RCTs with narrow confidence } \\
\text { intervals }\end{array}$ \\
II & $\begin{array}{l}\text { Systematic reviews of cohort studies or individual } \\
\text { good-quality cohort studies }\end{array}$ \\
III & $\begin{array}{l}\text { Systematic reviews of case-control studies or } \\
\text { individual good-quality case-control studies } \\
\text { Case series and poor-quality cohort and case-control } \\
\text { studies } \\
\text { IV }\end{array}$ \\
Vxpert opinion without explicit critical appraisal or \\
based on physiology or 'first principles'
\end{tabular}


Box 1: Questions addressed in the study (at the time all these were unlicensed uses or actions not mentioned or supported in the Summary of Product Characteristics for the products concerned)

\section{REGARDING PROGESTOGEN-ONLY FORMS OF}

CONTRACEPTION:

1 Do you advise women who weigh over $70 \mathrm{~kg}$ to take two pills per day to increase efficacy of the progestogen-only pill (POP)?

2 Is it acceptable to prescribe the progestogen-only emergency contraceptive pill (POEC) for a second time in a given cycle, if there is a second episode of risk?

3 Would you ever prescribe POEC beyond 5 days after the episode of unprotected intercourse but up to 5 days after calculated ovulation day?

4 Would you offer the progestogen implant (Implanon $\left.{ }^{\circledR}\right)$ to women taking enzyme-inducing anti-epileptic medication?

5 Would you offer the levonorgestrel intrauterine system (LNG-IUS) (Mirena $\left.{ }^{\circledR}\right)$ to women taking enzyme-inducing anti-epileptics?

6 In patients taking medications that induce liver enzymes how do you adjust doses of POEC?

\section{REGARDING THE END OF REPRODUCTIVE LIFE:}

7 Do you ever give some combination of hormone replacement therapy (HRT) and POP to women in the late reproductive years?

8 How do you effect a transition from combined oral contraceptive (COC) or POP to HRT at the menopause?

9 Do you prescribe the LNG-IUS as the progestogen for oestrogen opposition in postmenopausal HRT?

10 Do you permit use of the LNG-IUS beyond its licensed 5 years for ongoing birth control in a woman above age 40 ?

11 Do you permit the use of the LNG-IUS beyond its licensed 5 years for menorrhagia where birth control is not an issue?

12 Do you permit the use of the LNG-IUS beyond its licensed 5 years as part of (unlicensed) use of LNG-IUS plus HRT?

REGARDING THE COMBINED ORAL CONTRACEPTIVE:

13 Do you usually inform women of their option to 'tricycle' in the absence of a medical indication?

14 Do you usually inform women how to manipulate the pill taking routine so that withdrawal bleeds can be timed away from weekends?

15 How long do you consider it safe to prescribe the cyproterone acetate/oestrogen combined pill?

16 If the pill is an otherwise satisfactory choice, do you give special advice related to possible reduced effectiveness with Crohn's disease, ulcerative colitis or an ileostomy/total colectomy?

\section{QUESTIONS 17-21 RELATE TO THE FOLLOWING}

\section{CLASSIFICATIONS}

According to the World Health Organization (WHO) classification of contraceptive eligibility:2,45,46

1. A condition for which there is no restriction for the use of the contraceptive method ('A' = ALWAYS USABLE).

2 A condition where the advantages of the method generally outweigh the theoretical or proven risk ('B' = BROADLY USABLE).

3 A condition where the theoretical or proven risks generally outweigh the advantages. But - respecting the patient/client's autonomy - if she accepts the risks and rejects or should not use relevant alternatives, the method can be used with caution/additional care - as a 'method of last choice' (' $\mathrm{C}$ ' = CAUTION/COUNSELLING if used at all).

4 A condition that represents an unacceptable health risk. (' $\mathrm{D}$ ' = DO NOT USE).

In your practice, into which WHO Category for the COC would you place:

17 A woman with a single previous attack of erythema nodosum?

18 A woman with recent trophoblastic disease and elevated hCG?

19 A woman with a history of migraine with definite focal aura on one occasion more than 5 years ago?

20 A woman who was a heavy smoker for 20 years who completely stops smoking at 35 and wants to continue COC until she is 50 ?

21 A woman whose mother had breast cancer in her 40s?

Society of Consultants in Reproductive Health. Due to tight restrictions on release of the address list, details regarding responders and non-responders were not available.

\section{Design}

The questionnaire (Box 1) was designed on the basis of practical clinical experience and real-life dilemmas, following thorough literature review and a pilot study utilising six volunteer clinical medical officers. Mail-out to study participants was in May 2002 and non-responders were re-sent a questionnaire in June 2002. Data were gathered in the form of raw percentages for each answer.

\section{Results}

Of 205 consultants surveyed, 138 returned their questionnaire. This gave a response rate for the study's two mail-outs of $67 \%$.

\section{Discussion}

\section{Progestogen-only forms of contraception}

POP

Summary of Product Characteristics (SPC) advice. Manufacturers' guidelines for the traditional progestogenonly pills (POPs) available in the UK do not include comments regarding any change of dose for women of high body mass. ${ }^{4}$

Literature and guidelines review. The POP accounts for less than $10 \%$ of the oral contraceptive market in the UK. ${ }^{2}$ A report from the Oxford/Family Planning Association study 5 showed a trend to higher pregnancy rates in women taking a POP, with increasing weight of the woman, although this was not statistically significant (possibly because most failures were failures of the users not the method). This and an Australian study showing that cervical mucus was only unaffected by a POP in three very overweight women ${ }^{6}$ has led to concern amongst practitioners $^{7}$ that women of high body mass would have an increased failure rate. One suggested solution is to recommend that such women take two POPs a day. ${ }^{1}$ Other authoritative texts make no mention of the issue, 8,9 or imply no special action since there is no confirmation. ${ }^{10} \mathrm{~A}$ review article, published after this study, finds no good evidence, but suggests double dosing is likely to be the safest option in young women weighing over $70 \mathrm{~kg} .{ }^{11}$ Consultants' responses. This study showed a majority of consultants $(71 \%)$ recommend doubling the dose of POP for women of high body mass.

Comments. The new POP, Cerazette ${ }^{\circledR}, 12$ contains $75 \mathrm{ug}$ desogestrel, functionally a much higher dose than the older POPs. Since the available data suggest it usually acts as an anovulant, and dose adjustments for body mass are not made for any other anovulant products, pending more data a trend to using this POP in usual dosage for overweight women can be predicted.

\section{Progestogen-only emergency contraception (POEC)}

Pregnancy rates from any single episode of intercourse are low ${ }^{13}$ and progestogen-only emergency contraception (POEC) effectiveness is good. ${ }^{14}$ This means that to answer many of the questions regarding particular scenarios for optimising prescribing practice, studies would need to be exceptionally large and may never be done.

\section{Using a second time in the same cycle}

SPC advice. Evidence for teratogenicity of progestogens at very high doses in animal studies, ${ }^{14}$ and the implications related to laws on induced abortion in many countries, cause producers to be wary of advocating repeated dosing in a given cycle. Current advice from Schering, the drug company that produces POEC as Levonelle ${ }^{\circledR}$ in the UK, $, 4,15$ states that epidemiological studies indicated no adverse effects of progestogens on the fetus. However, they also state that "repeated administration within a menstrual cycle is not advisable because of the possibility of disturbances of the cycle, but it can be used more than once if the need arises". 
Table 2 Summary of responses to study questionnaire ${ }^{\mathrm{a}}$

\begin{tabular}{|c|c|c|c|c|}
\hline \multirow[t]{2}{*}{ Questions } & \multicolumn{2}{|l|}{ Yes } & \multicolumn{2}{|l|}{ No } \\
\hline & $\mathrm{n}$ & $\%$ & $\mathrm{n}$ & $\%$ \\
\hline $\begin{array}{l}1 \text { POP dose doubled for } \\
\text { women of high body mass? }\end{array}$ & 98 & 71 & 40 & 29 \\
\hline $\begin{array}{l}2 \text { POEC prescribed for } \\
\text { second episode of risk in a } \\
\text { cycle? }\end{array}$ & 138 & 100 & 0 & 0 \\
\hline $\begin{array}{l}3 \text { POEC prescribed up to } \\
5 \text { days after ovulation } \\
\text { but }>5 \text { days since episode } \\
\text { of risk? }\end{array}$ & 64 & 46 & 73 & 53 \\
\hline $\begin{array}{l}4 \text { Implanon }{ }^{\circledR} \text { prescribed for } \\
\text { contraception to women } \\
\text { on EIDs? }\end{array}$ & 54 & 39 & 81 & 59 \\
\hline $\begin{array}{l}5 \text { LNG-IUS prescribed for } \\
\text { contraception for women } \\
\text { on EIDs? }\end{array}$ & 129 & 93 & 6 & 4 \\
\hline $\begin{array}{l}6 \text { POEC dose adjustment for } \\
\text { women on EIDs? }\end{array}$ & $\begin{array}{l}59 \text { (double } \\
\text { first dose } \\
\text { only) }\end{array}$ & 43 & $\begin{array}{l}66 \text { (double } \\
\text { both doses) }\end{array}$ & le 48 \\
\hline $\begin{array}{l}7 \text { POP given with HRT in } \\
\text { late reproductive years? }\end{array}$ & Withdrawn & & Withdrawn & \\
\hline $\begin{array}{l}8 \text { Median upper age of } \\
\text { transfer from COC to } \\
\text { HRT? }\end{array}$ & $\begin{array}{l}84 \\
(50 \text { years })\end{array}$ & 61 & & \\
\hline $\begin{array}{l}9 \text { LNG-IUS prescribed as } \\
\text { the progestogen for } \\
\text { oestrogen opposition in } \\
\text { postmenopausal HRT? }\end{array}$ & 110 & 80 & 25 & 18 \\
\hline $\begin{array}{l}10 \text { LNG-IUS prescribed } \\
\text { beyond } 5 \text { years for } \\
\text { contraception? }\end{array}$ & 48 & 35 & 86 & 62 \\
\hline $\begin{array}{l}11 \text { LNG-IUS prescribed } \\
\text { beyond } 5 \text { years for } \\
\text { menorrhagia? }\end{array}$ & 98 & 71 & 38 & 28 \\
\hline $\begin{array}{l}12 \text { LNG-IUS prescribed } \\
\text { beyond } 5 \text { years for part } \\
\text { of HRT? }\end{array}$ & 50 & 36 & 83 & 60 \\
\hline $\begin{array}{l}13 \text { Women informed routinely } \\
\text { of option to tricycle COC? }\end{array}$ & 32 & 23 & 106 & 77 \\
\hline $\begin{array}{l}14 \text { Women informed routinely } \\
\text { of option to manipulate } \\
\text { periods on COC? }\end{array}$ & 74 & 54 & 64 & 46 \\
\hline $\begin{array}{l}15 \text { Median maximum duration } \\
\text { of cyproterone } \\
\text { acetate/oestrogen use? }\end{array}$ & $\begin{array}{l}29 \\
(5 \text { years })\end{array}$ & 21 & & \\
\hline $\begin{array}{l}16 \text { Advise re decreased } \\
\text { effectiveness of COC } \\
\text { in women with Crohn's } \\
\text { disease, ulcerative colitis } \\
\text { or an ileostomy? }\end{array}$ & 111 & 80 & 25 & 18 \\
\hline $\begin{array}{l}\text { WHO categories for COC } \\
\text { contraindications }\end{array}$ & $\begin{array}{l}\text { WHO } 1 \\
(\%)\end{array}$ & $\begin{array}{l}\text { WHO } 2 \\
(\%)\end{array}$ & $\begin{array}{l}\text { WHO } 3 \\
(\%)\end{array}$ & $\begin{array}{l}\text { WHO } 4 \\
(\%)\end{array}$ \\
\hline $\begin{array}{l}17 \text { Single previous attack of } \\
\text { erythema nodosum }\end{array}$ & 8 & 45 & 31 & 6 \\
\hline $\begin{array}{l}18 \text { Recent trophoblastic disease } \\
\text { and elevated hCG levels }\end{array}$ & 4 & 4 & 11 & 82 \\
\hline $\begin{array}{l}19 \text { One migraine with focal aura } \\
\text { more than } 5 \text { years ago }\end{array}$ & 1 & 11 & 43 & 44 \\
\hline $\begin{array}{l}20 \text { Ex-heavy smoker who stops } \\
\text { at } 35 \text { years }\end{array}$ & 7 & 28 & 52 & 12 \\
\hline $\begin{array}{l}21 \text { Woman whose mother had } \\
\text { breast cancer in her } 40 \mathrm{~s}\end{array}$ & 5 & 57 & 35 & 2 \\
\hline
\end{tabular}

aWhere percentages do not add up to $100 \%$ this is due to rounding or missing responses.

COC, combined oral contraceptive; EIDs, enzyme-inducing drugs; hCG, human choriogonadotrophin; HRT, hormone replacement therapy; LNGhuman choriogonadotrophin; HRT, hormone replacement therapy; LNG-
IUS, levonorgestrel intrauterine system; POEC, progestogen-only emergency contraception; POP, progestogen-only pill.

Literature and guidelines review. Some practitioners have published the view that in the absence of clear risk, the risk/benefit analysis weighs in the direction of repeat prescribing: "[the] absence of demonstrable teratogenicity of oral contraceptives suggest [it be] ... contraindicated only because it does not work". 13 Repeat prescribing is also permitted in the Practice Guidance of the UK Faculty of Family Planning and Reproductive Health Care. ${ }^{16}$
Consultants' responses. Results in this study show clearly that $100 \%$ of consultants will prescribe POEC more than once in a cycle.

Offering POEC not later than 5 days after calculated ovulation but beyond 5 days after a single exposure SPC advice. The producers only recommend use up to 72 hours after a single act of unprotected intercourse. ${ }^{15}$ Literature and guidelines review. Until late 2002, published studies on POEC ${ }^{13,14}$ had shown useful efficacy up to 72 hours but did not include sexual exposure earlier than this. A recent paper by von Hertzen et al. ${ }^{17}$ (not available at the time of this survey) provides some evidence of efficacy between 72 hours and 5 days after a single exposure. However, due to low power, the confidence intervals are wide. Moreover, that study does not provide data to support the use of POEC up to 5 days after ovulation [on which basis POEC might be used, like a copper intrauterine device (IUD), more than 5 days after the earliest sexual exposure]. Though progestogens may interfere with implantation, which is generally assumed to begin at 5 days postovulation, the contribution of this effect to the efficacy of POEC (as opposed to a copper IUD) is believed to be small. An added problem is that the ovulation day is notoriously difficult to work out. 18 Recent Faculty guidelines state that "a recommendation for use beyond 72 hours cannot be given". 16

Consultants' responses. This study found $46 \%$ of consultants would prescribe POEC up to the fifth day postovulation. The remainder, however, would not, providing no clear guidance for practice.

Progestogenic forms of contraception and women using liver enzyme-inducing drugs (EIDs)

Since progestogens are metabolised by the liver, and higher doses of the regular POP are advised in women on liver enzyme-inducing drugs (EIDs), ${ }^{19}$ adjustments may be required for other progestogenic contraceptives.

\section{Etonogestrel implant}

SPC advice. The recommendation is that women on longterm EIDs choose an alternative form of contraception. ${ }^{4}$ Literature review. Cases of contraceptive failure in women on EIDs have been documented for levonorgestrel implants $\left(\right.$ Norplant ${ }^{\circledR}$ ), which normally have an exceptionally low failure rate. ${ }^{19}$ This is compatible with reports also of lowered plasma levonorgestrel levels. By analogy, efficacy of the newer etonogestrel implant (Implanon ${ }^{\circledR}$ ) will also be lowered in women on EIDs, though this had not been formally studied prior to marketing.

Consultants' responses. This study shows that $59 \%$ of consultants are not happy to give Implanon to these women and a further $13 \%$ offered caveats to advice on decreased efficacy.

\section{LNG-IUS}

SPC advice. " ... the effect of hormonal contraceptives may be impaired by drugs which induce liver enzymes. The influence of these drugs on the efficacy of Mirena ${ }^{\circledR}$ has not been studied." 4

Literature and guidelines review. A recent cross-sectional pilot study of just 56 women ${ }^{20}$ found a failure rate of around 1 per 100 woman-years for the levonorgestrel intrauterine system (LNG-IUS) in women on enzyme-inducing agents. This rate, while higher than the recognised 0.2 per 100 women-years for the method, usually, ${ }^{1}$ is not dissimilar to other forms of reliable contraception and might be expected, given the high local concentration of levonorgestrel released at the site of action. Further larger studies are obviously required. 
Consultants' responses. The lead consultants in this study offer majority opinion (93\%) that the LNG-IUS is acceptable contraception for women taking EIDs.

\section{POEC}

SPC advice. The product information for the POEC, Levonelle ${ }^{\circledR}, 15$ lists EIDs as suspected of having the capacity to reduce contraceptive efficacy. It gives no specific recommendations for managing this interaction. Literature and guidelines review. Studies have shown both increases in the international normalised ratio levels from warfarin interaction in women taking POEC ${ }^{21}$ and likely decreases in hormonal contraceptive efficacy with other enzyme inducers, in particular St John's Wort (hypericum). ${ }^{22}$ Most authorities recommend adding a third tablet to the regime 2,16 (based on experience with regular use of oestrogen-containing combined pills that a $50 \%$ dose increase will suffice). Others double the total dose.

Consultants' responses. This study reveals that only a tiny minority of consultants (2/134 respondents to the question) would neither increase the dose of emergency contraception in some way - nor even advise the copper IUD method for all EID users. However, no majority recommendation of exactly how to do this emerged, as roughly equal numbers of consultants double only the first dose as double both doses.

\section{Regarding the end of reproductive life}

Combination of HRT and POP

In the perimenopausal hormone replacement therapy (HRT) taker there is often a need for contraception Unfortunately, the question regarding using POP in this situation was ambiguous and interpreted in different ways by respondents; hence valid conclusions cannot be drawn.

\section{Transfer of COC to HRT}

$S P C$ advice. Product information for both combined oral contraceptives (COCs) and HRT options do not discuss this scenario.

Literature and guidelines review. Lack of evidence in this area results in a lack of consistency for practice. A common recommendation is not to use COCs beyond age 50 years ${ }^{3}$ given increasing risks with age and sharply diminishing need for such a powerful contraceptive.

Consultants' responses. Several complex protocols for transfer from hormonal contraception to HRT were offered by study respondents, with divergent views on the need for serial follicle-stimulating hormone estimations. Regarding the age at which to stop the COC, a majority of consultants $(69 \%)$ chose age 50 years, and minorities of $10 \%$ each chose either age 52 or 54 years.

\section{The LNG-IUS (Mirena) in the perimenopause}

Unopposed oestrogen is recognised as predisposing women to endometrial hyperplasia and potentially to carcinoma Hence the standard recommendation, that all nonhysterectomised women take progestogen with the oestrogen of HRT. With the arrival of the LNG-IUS, it was suggested that the local uterine progestogen provided by the IUS may suffice.

SPC advice. Unlike some other countries, in the UK the manufacturer's licence does not yet cover use of the LNGIUS for this purpose. ${ }^{4,15}$

Literature and guidelines review. Recent studies have investigated the clinical, endometrial and metabolic response to the LNG-IUS ${ }^{23,24}$ in women receiving HRT, and, in common with several texts, $, 1,8$ conclude that the LNG-IUS can be used successfully and safely as part of HRT.
Consultants' responses. This study found that $80 \%$ of lead practitioners are in favour of and do offer this use.

\section{Duration of use of the LNG-IUS}

\section{For contraception}

SPC advice. Product information recommends use only to 5 years. ${ }^{4,15}$

Literature and guidelines review. Device changing is recognised as potentially causing most of the unwanted effects of IUDs. It has generally been accepted since $1990^{25}$ that among women who have a copper device fitted over 40 years of age, it is acceptable to leave it in until beyond the menopause. Low pregnancy rates with the LNG-IUS extending out to 5 years (for which it is licensed), 26 and one study of use to 7 years with no pregnancies in the sixth and seventh years, ${ }^{27}$ are somewhat reassuring about use until then - but no longer.

Consultants' responses. Despite the above, this study found the majority of consultants are not keen to allow extended use of the device beyond 5 years.

\section{For endometrial protection}

SPC advice. As the product is not licensed for this indication, advice on duration of use for this does not exist. Literature and guidelines review. Continued endometrial protection against neoplasia must be assured for continued use of the LNG-IUS as part of HRT: there is a paucity of evidence for this.

Consultants' responses. Most consultants (62\%) in this study were unhappy with extended prescribing for this use.

\section{For menorrhagia}

SPC advice. Product information, as above, recommends use to 5 years..$^{4,15}$

Literature and guidelines review. No evidence was found for this. However, for menorrhagia in the absence of any need for contraception, maintained clinical response is the issue.

Consultants' responses. Here the trend is certainly the other way, with a majority of consultants (72\%) happy to continue use while menorrhagia is controlled: the treatment is only for symptoms and it will be easy to tell when the effect has been lost. Nevertheless, responses were not unanimous.

\section{COC pill}

\section{Manipulation of cycle}

SPC advice. Product information contains no information regarding manipulation of cycles and bleeds ${ }^{4,15}$ aside from occasional one-cycle postponement for holidays, and so on. Literature and guidelines review. The practice of running packets of active pills together and avoiding one or more withdrawal bleeds is often referred to as 'tricycling' (as the usual recommendation is three to four packets or 3 months of active treatment before a pill-free interval leading to a withdrawal bleed). This may be advised in women who need to avoid menses for medical or social reasons - but it is also a choice. $1,2,28$ The pill-free interval is of theoretical importance in allowing recovery from some systemic (e.g. lipid) effects of the pill, and there is some concern regarding the increased annual doses of hormone in women who tricycle. Evidence to support or refute either of these concerns is lacking. Recent recommendations state that women 'may' be advised of these options. ${ }^{29}$

Consultants' responses. In this study a majority of consultants indicated they do not routinely inform clients of the option to tricycle in the absence of a medical indication, though 30/106 of the 'No' responders commented they would if there was a medical indication and 18 said they would for holidays and special occasions. 
Regarding manipulation of the regular timing of withdrawal bleeds, practitioners were roughly equally divided on whether or not they would inform clients. Sixteen respondents felt this was likely to confuse patients, although 21 of the 'No' responders did indicate that they would inform the client of the option if led by the client Comments. At the first consultation when a woman of any age is first prescribed the COC there is a lot of information to impart to ensure use will be safe and effective. Many practitioners are reluctant to clutter this consultation with non-essential information. The question was therefore carefully worded in this study to include informing clients at subsequent consultations.

Perhaps the reluctance of study respondents derives from fear that the subsequent debate with the user as regards 'pros' and 'cons' will be too time-consuming. This may be interpreted as safe, to minimise confusion and perhaps maximise compliance, or as due to the above theoretical concerns about higher total oestrogen dosing over the year. It may also be interpreted as 'paternalistic', the practitioner deciding whether the woman should bleed monthly or not.

\section{The cyproterone acetate/oestrogen combined pill}

SPC advice. Regarding duration of use, the SPC ${ }^{15}$ suggests ceasing medication when acne or hirsutism resolves and recommencing if recurrence occurs, but does not offer a maximum duration.

Literature and guidelines review. The long-term use of the cyproterone acetate/oestrogen combined pill for its antiandrogen effects on acne and hirsutism is associated with some concerns. It is an oestrogen-dominant product and has a higher risk of venous thromboembolism than levonorgestrel-containing oral contraceptives. ${ }^{30,31} \mathrm{An}$ association with liver tumours has been described in animal studies. Studies from the past decade ${ }^{32,33}$ are somewhat reassuring that cyproterone acetate use is no more associated with an increased incidence of liver tumours than other COCs.

Consultants' responses. This study found that a majority of consultants $(63 \%)$ felt treatment should last 5 years or less, the median nominated maximum duration $(21 \%$ of respondents) being 5 years. Some $20 \%$ of consultants considered that there need be no maximum duration.

\section{COC in inflammatory bowel disease}

SPC advice. Producers of COCs have a standard warning regarding diarrhoea, and warn of an association of inflammatory bowel disease with 'circulatory events' However, specific advice is not given. ${ }^{4}$

Literature and guidelines review. The issue in question here is whether special advice is given regarding reduced effectiveness of the COC, through gut absorption being affected by Crohn's disease, ulcerative colitis or a colectomy. Given that most absorption occurs in the jejenum, which is not affected in ulcerative colitis or by ileostomy or total colectomy, there should only be an issue for women with Crohn's disease suspected of affecting the jejunum. ${ }^{34}$

Consultants' responses. Despite these facts, $81 \%$ of respondents made no distinction between the listed conditions and do give special advice regarding decreased effectiveness

Comments. Respondents may have been concerned by the possibility that the enterohepatic recirculation of ethinylestradiol (alone of the two COC hormones), after breakdown of its metabolites by the large bowel flora, could be an important factor in efficacy at least in some (unidentifiable) individuals. ${ }^{1}$

\section{COC contraindications}

Many medical conditions exist that can be caused by or exacerbated by the COC. The World Health Organization (WHO) (http://www.who.int/reproductive-health/family planning) uses the preferred term 'medical eligibility criteria' and classifies conditions into four categories (as outlined in the introductory section above). The appropriate category as the basis from which to advise patients has not been agreed by WHO for all conditions and is not always clear from the literature. This poses a challenge for the nonexpert practitioner, especially in the case of rarely encountered scenarios. Current guidance for selected conditions was sought by this study.

SPC advice. Review of the SPCs for COCs revealed no specific guidance in these areas except for migraine (with/without aura not specified) as a relative contraindication, and a warning that worsening of severity or frequency of migraine can be a reason to stop COCs. ${ }^{4}$

\section{Erythema nodosum}

Literature and guidelines review. Erythema nodosum is a cutaneous response to a variety of apparently unrelated infectious and disease processes. Erythema nodosum has been described in association with the COC. However, a causative association has not been clearly established. ${ }^{1}$ Consultants' responses. The majority (87\%) of respondents chose Category 2 or 3 , suggesting that cautious retrial is generally acceptable, presumably in part because of the benign nature of the condition.

\section{Trophoblastic disease}

Literature and guidelines review. Trophoblastic disease is a tumour of pregnancy in which chromosomal abnormalities lead to abnormal cellular proliferation. The tumour produces human chorionic gonadotrophin (hCG) and the tumour is considered cured when hCG levels are undetectable. There is a concern in the UK literature that taking contraceptive hormones prior to hCG reaching undetectable levels doubles the chance of the patient requiring chemotherapy for choriocarcinoma. ${ }^{35}$ However, WHO classifies it (http://www.who.int/reproductivehealth/family_planning) as WHO Category 1 . This is based apparently on the North American literature, 36 which favours the opinion that use of oral contraceptive hormones has no bearing on outcome - but this is in the context of a very low threshold for giving chemotherapy from the time of diagnosis.

Consultants' responses. This study found $82 \%$ of respondents chose WHO Category 4.

Comments. Consultants in the UK clearly still follow the recommendation from older studies from the Charing Cross Hospital ${ }^{35}$ and UK texts $3,9,22,29$ to avoid hormonal contraception in women with trophoblastic disease up to, but not after, the point that hCG is undetectable.

Migraine (definite focal aura on one occasion more than 5 years ago)

Literature and guidelines review. Studies show an increased risk of ischaemic stroke in migraine sufferers on COC compared to hospital controls ${ }^{37}$ and an up to eightfold increase in ischaemic stroke in sufferers of migraine with focal aura, compared to those without focal aura. ${ }^{38}$ On the strength of these studies, strong recommendations regarding risk Category $4^{29}$ are generally made for women with a history of migraine with aura, but generally only Category 2 for women with migraine without aura if they have no other risk factors for ischaemic stroke.

Consultants' responses. This study found that experts are cautious and will either never or only in exceptional 
circumstances prescribe a COC to a woman who has had a single migraine with aura more than 5 years before. While $43 \%$ do concede Category 3, this still means that an alternative would be preferred.

Comments. These results remind all clinicians to remain vigilant for this contraindication with potentially catastrophic consequences.

Smoking (heavy smoker for 20 years who completely stops smoking at 35 and wants to continue COC until she is 50) Literature and guidelines review. Clear guidance exists in the UK that the COC should be discontinued in women over 35 years of age who smoke. ${ }^{1,2,10,29}$ This question, however, poses an often encountered problem. When faced with having their favoured, reliable and convenient form of contraception withdrawn, some women actually cease smoking. How then should those 20 years of prior smoking and consequent arterial vascular damage be taken into account? Two observational studies suggest that cardiovascular risk for smokers declines rapidly after giving up, reaching levels comparable with those of people who have never smoked by $2-4$ years. ${ }^{39,40}$ Clinicians remain aware that the patient who has just given up smoking may not manage to remain a non-smoker, and that there are now many equally effective alternatives to the COC.

Consultants' responses. Respondents in this study generally remain cautious, with $64 \%$ choosing Category 3 or 4 for this scenario.

Strong family history of breast cancer (mother had breast cancer in her 40s)

Literature and guidelines review. Results from the literature are conflicting as to whether the attributable added risk of breast cancer from the COC is the same for this woman as for other women ${ }^{41}$ or is higher. ${ }^{42}$ Attempts have been made to identify exactly which women, with which genetic background, are likely to be taking greatest risk. ${ }^{43,44}$ The majority of breast cancers are not due to genetic mutations, but women with certain mutations (particularly BRCA $^{1}$ ) may have a small additional risk of breast cancer if taking the COC. ${ }^{44}$ The situation is complicated by the significant risk of ovarian cancer in these women, the risk of which may be reduced by taking COCs. ${ }^{1}$

Consultants' responses. Most respondents in this study classify breast cancer in the mother aged less than 40 years as a relative contraindication (WHO 2 and 3), indicating they would encourage women to consider other contraceptive options.

\section{Conclusions}

This study describes the practice of consultants in reproductive health in areas where dilemmas in contraceptive clinical management have been identified. For each of these areas at the time of the study the published evidence was inadequate to provide clear-cut guidance.

A summary of responses of lead consultants to the study questions is provided in Table 2. Question 2 had a unanimous response and Questions 1, 5, 9,11, 13 and 16 show responses of greater than $70 \%$ in one direction, which could give useful guidance. The responses to questions on WHO categories (e.g. Questions 17, 19 and 20) also show interesting trends when compared with standard recommendations. One striking aspect of these results is that consultants have indicated that their practice habits can be different from the pharmaceutical company's advice (notably Questions 1, 2, 9, 11 and 13). This means the practice is unlicensed and hence - though medico-legal risk can be minimised by the 'named patient' $\operatorname{protocol}^{1,2}-$ if there is an adverse outcome, then the practitioner (not the pharmaceutical company) takes the risk.
Nevertheless, for the non-expert practitioner the results of this survey provide a degree of reassurance that some flexibility in prescribing is acceptable. It is to be hoped that, in time, WHO's policy of repeated evidence-based revisions of their Medical Eligibility Criteria for Contraceptive $\mathrm{Use}^{45}$ and their Selected Practice Recommendations for Contraceptive Use ${ }^{46}$ which are seen as 'guidelines for guidelines' (intended for adaptation by consensus, as appropriate for each country or region) will lead to better guidance for prescribers - even in medical areas where good data are lacking. In the UK, this process of adaptation has begun. ${ }^{47}$

\section{Acknowledgements}

Dr Lin Fritschi from the University of Western Australia provided supervision and editorial advice for the original thesis. Gratitude is expressed to the members of the Society of Consultants in Reproductive Health for giving freely of their time to fill in the questionnaire, and to the secretary Shonda Powell for her work in mailing out questionnaires. Thanks are also due to Alison Orr for dedicated practical assistance.

\section{Statements on funding and competing interests}

Funding. Funding for the printing and posting of questionnaires was obtained from the Margaret Pyke Memorial Trust in the form of a grant. Competing interests. John Guillebaud has received lecture fees, expenses, research grants and payments for ad hoc consultancy work from the manufacturers of contraceptive products.

References

1 Guillebaud J. Appendix A. Contraception - Your Questions Answered (3rd, 4th edns). Edinburgh, UK: Churchill Livingstone, 1999, 2004

2 Guillebaud J. Contraception Today (5th edn). London, UK: Martin Dunitz, 2004.

3 Phillips B, Ball C, Sackett D, et al. Levels of Evidence and Grades of Recommendations. Oxford Centre for Evidence-based Medicine Recommendations. Oxford Centre for Evidence-based Medicine of evidence.asp. November 1998

4 UK Data Sheet Compendium. http://www.emc.medicines.org.uk [Accessed April 2004].

5 Vessey MP, Villard-Mackintosh L, Yeates D. Effectiveness of progestogen-only oral contraceptives. Br J Fam Plann 1990; 16: 79.

6 Kovacs G, Hendricks J, Summerbell D, et al. A pre-coital pill? A preliminary in vitro study. Br J Fam Plann 2000; 26: 165-166.

7 Guillebaud J. Progestogen-only pills (POPs) and body weight. J Fam Plann Reprod Health Care 2001; 27: 239.

8 Kubba A, Sanfilippo J, Hampton N. Contraception and Office Gynaecology. London, UK: W B Saunders, 1999.

9 Hatcher RA, Trussell J, Stewart F, et al. (eds). Contraceptive Technology. New York, NY: Ardent Media Inc., 1998.

10 Glasier A, Gebbie A. Handbook of Family Planning and Reproductive Health Care (4th edn). London, UK: Churchill Livingstone, 2000

11 de Souza A, Brechin S, Penney G. The members' enquiry service: frequently asked questions. J Fam Plann Reprod Health Care 2003; 29(3): 160-161

12 Brechin S, Penney G, de Souza A. New Product Review (April 2003) Desogestrel-only pill (Cerazette). J Fam Plann Reprod Health Care 2003; 29(3): 162-164.

13 Glasier A. Emergency postcoital contraception. N Engl J Med 1997; 337: $1058-1064$.

14 Task Force on Postovulatory Methods of Fertility Regulation. Randomised controlled trial of levonorgestrel versus the Yuzpe regimen of combined oral contraceptives for emergency contraception. Lancet 1998; 352: 428-433.

15 Schering website. http://www.schering.co.uk/content/health_pros (updated November 2003).

16 Faculty of Family Planning and Reproductive Health Care Clinical Effectiveness Unit. FPPRHC Guidance. Emergency contraception. $J$ Fam Plann Reprod Health Care 2003; 29(2): 9-16.

17 von Hertzen H, Piaggio G, Ding J, et al. Low dose mifepristone and two regimens of levonorgestrel for emergency contraception: a WHO multicentre randomised trial. Lancet 2002; 360: 1803-1810.

18 Wilcox AJ, Dunson D, Baird D. The timing of the "fertile window" in the menstrual cycle: day specific estimate from a prospective study. BMJ 2000; 321: 1259-1262.

19 Crawford P. Interactions between antiepileptic drugs and hormonal contraception. CNS Drugs 2002; 16: 263-272.

20 Bounds W, Guillebaud J. Observational series on women using the contraceptive Mirena concurrently with anti-epileptic and other enzyme-inducing drugs. J Fam Plann Reprod Health Care 2002; 28 $78-80$.

21 Ellison J, Thomson, AJ, Greer IA, et al. Drug points: apparent 
interaction between warfarin and levonorgestrel used for emergency contraception. $B M J 2000 ; 321: 1382$

22 Ratz AE, von Moos M, Drewe J. St John's Wort: a pharmaceutica with potentially dangerous interactions. Schweiz Rundsch Med Prax 2001; 90: 843-849.

23 Varila E, Wahlstrom T, Rauramo I. A 5-year follow-up study on the use of a levonorgestrel intrauterine system in women receiving hormone replacement therapy. Fertil Steril 2001; 76: 969-975.

24 Hubacher D, Grimes DA. Non-contraceptive health benefits of intrauterine devices: a systematic review. Obstet Gynaecol Surv 2002; 57: $120-128$.

25 Newton J, Tacchi D. Long term use of copper intrauterine devices. A statement from the Medical Advisory Committee of the Family Planning Association and the National Association of Family Planning Doctors. Lancet 1990; 335: 1322-1323.

26 Sivin S, el Mahgoub S, McCarthy T, et al. Long term contraception with levonorgestrel 20mcg/day (Lng 20) and CopperT 380Ag intrauterine devices: a 5 year randomized study. Contraception 1990 42: $361-378$.

27 Sivin I, Stern J, Coutinho E, et al. Prolonged intrauterine contraception: a seven-year randomized study of the levonorgestre 20mcg/day (Lng 20) and CopperT 380Ag IUDS. Contraception 1991; 44: 473-480.

28 Kaunitz AM. Menstruation: choosing whether ... and when. Contraception 2000; 62: 277-284.

29 Faculty of Family Planning and Reproductive Health Care Clinical Effectiveness Unit. FPPRHC Guidance (October 2003). First prescription of combined oral contraception. J Fam Plann Reprod Health Care 2003; 29(4): 209-223.

30 Committee for the Safety of Medicines/Medicines Control Agency (CSM/MCA). Cyproterone acetate (Dianette): risk of venous thromboembolism. Curr Probl Pharmacovigilance 2002; 28: 9-10. http://www.mca.gov.uk.

31 Vasilakis-Scaramozza C, Jick H. Risk of venous thromboembolism with cyproterone or levonorgestrel contraceptives. Lancet $2001 ; 358$ $1427-1429$

32 Rabe T, Feldman K, Heinemann L, et al. Cyproterone acetate: is it hepato- or genotoxic? Drug Saf 1996; 14: 25-38.

33 The Collaborative MILTS Project Team. Oral contraceptives and liver cancer - results of the Multicentre International Liver Tumour Study. Contraception 1997; 56: 275-284.

34 Faculty of Family Planning and Reproductive Health Care Clinical Effectiveness Unit. FPPRHC Guidance (July 2003). Contraceptive choices for women with inflammatory bowel disease. I Fam Plann Reprod Health Care 2003; 29(3): 127-135.

35 Stone M, Bagshawe KD. An analysis of the influences of materna age, gestational age, contraceptive method and the mode of primary treatment of patients with hydatidiform moles on the incidence of subsequent chemotherapy. Br J Obstet Gynaecol 1979; 86: 782-792.

36 Gerulath $\mathrm{AH}$, Ehlen TG, Bessetle P, et al. Gestational trophoblastic disease. J Obstet Gynaecol Can 2002; 24: 434-446.

37 Tzourio C, Tehindrazanarivelo A, Igle'sias S, et al. Case-control of migraine and risk of ischaemic stroke in young women. BMJ 1995 310: $830-833$.

38 Carolei A, Marini C, De Matteis G and the Italian National Research Study Council Group on Stroke in the Young. History of migraine and risk of cerebral ischaemia in young adults. Lancet 1996; 347: $1503-1506$.

39 United States Department of Health and Human Services. The Health Benefits of Smoking Cessation: A Report of the Surgeon General. DHHS Publication No. (CDC) 90-8416. Rockville, MD: United States Public Health Service, Office on Smoking and Health, 1990.

40 Kawachi CI, Colditz GA, Stampfer MJ, et al. Smoking cessation in relation to total morbidity rates in women: a prospective cohort study. Ann Intern Med 1993; 119: 992-1000.

41 Marchbanks P, McDonald J, Wilson H, et al. Oral contraceptives and their risk of breast cancer. N Engl J Med 2002; 346: 2025-2032.

42 Grabrick D, Hartmann L, Cerhan J, et al. Risk of breast cancer with oral contraceptive use in women with a family history of breast cancer. JAMA 2000; 284: 1791-1798.

43 Friedenson B. A current perspective of genetic testing for breast and ovarian cancer: the oral contraceptive decision (Review). MedGenMed 2001; 3(4). http://www.medscape.com/viewarticle/ 408191 [Accessed 5 January 2004].

44 Narod SA, Dube MP, Klijn J. Oral contraceptives and the risk of breast cancer in BRCA 1 and BRCA 2 mutation carriers. $J$ Nat Cancer Inst 2002; 94: 1773-1770.

45 World Health Organization (WHO). Medical Eligibility Criteria for Contraceptive Use. Geneva, Switzerland: WHO, 2000

46 World Health Organization (WHO). Selected Practice Recommendations for Contraceptive Use. Geneva, Switzerland: WHO, 2002

47 Glasier A, Brechin S, Raine R, et al. A consensus process to adapt the World Health Organization Selected Practice Recommendations for UK use. Contraception 2000; 68: 327-333.

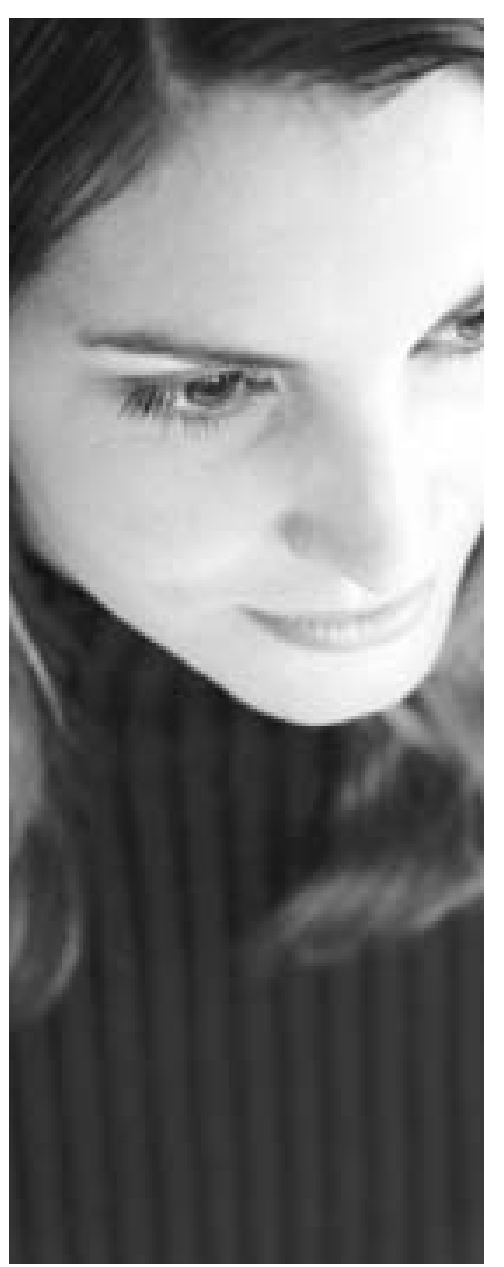

Termination of Pregnancy

\section{Fast, confidential, caring. The professional choice.}

Marie Stopes International is a leading charity in the field of family planning. We work closely with the NHS to provide termination of pregnancy services and are also happy to accept private referrals.

At centres around the UK we offer a professional and convenient service. You can trust us to take care of the patients you refer. We're discreet, confidential, sympathetic and will do everything we can to make a difficult time easier. Patients can also rely on our full aftercare service including post abortion counselling.

If your patient would like an appointment or if you would like to find out more about us, simply call the number below. We will be happy to send you an information pack containing full details of our services and some easy to use referral forms. Alternatively, you can visit our web site.

\section{Call us on 08453001212} or visit www.mariestopes.org.uk

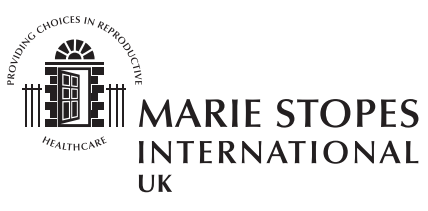

Journal of Family Planning and Reproductive Health Care 2004: 30(4) 


\section{MEMBERSHIP OF THE FACULTY OF FAMILY PLANNING AND REPRODUCTIVE HEALTH CARE}

The MFFP Examination consists of:

Part 1 (A or B) New format Multiple Choice Question paper (MCQ)

Part 1A Examination: For those who have not passed the Part 1 MRCOG nor received exemption from Part $1 \mathrm{MRCOG}$. This 2-hour paper consists of $60 \mathrm{MCQs}$ based on basic, applied and clinical science.

Part 1B Examination: For those who have passed the Part 1 MRCOG or have received exemption from Part $1 \mathrm{MRCOG}$ and wish to be exempt from the basic science component of the Part 1A. This 11/2-hour paper consists of 45 MCQs based on clinical and applied science.

Part 1 (A and B) examinations will be held on Tuesday 5 April 2005 (applications must be received by 1 January 2005) and on Friday 21 October 2005 (applications must be received by 1 July 2005).

Part 2 Examination (Dissertation or Case Reports)

\section{$\square \quad$ Part 2 - Dissertation or Case Reports}

Submission of one Dissertation (10 000 words) or two Case Reports (2500 \pm 500 words each).

Approval of the Dissertation or Case Reports titles by the Dissertation/Case Reports Convenor must be obtained before the candidate starts work on the Dissertation or Case Reports and before the candidate applies to sit the Part 2 (CRQ, MEQ, OSCE) component. Guidance notes and proposal form, plus exemption form/information, are available on request (see below).

Part 2 Examination (CRQ, MEQ, OSCE)

\section{- Part 2 - CRQ, MEQ, OSCE}

Critical Reading Question examination paper (CRQ)

Modified Essay Question examination paper (MEQ)

Objective Structured Clinical Examination (OSCE)

Applications for the Part 2 held in June 2005 must be received by 1 December 2004.

Please consult the revised Examination regulations (June 2004) for changes to entry requirements.

The qualification is subject to re-certification every 5 years.

Revised regulations (June 2004), application forms and dissertation documents are available on application to: Miss Denise Newell, Examination Secretary, Faculty of Family Planning and Reproductive Health Care of the Royal College of Obstetricians and Gynaecologists, 27 Sussex Place, Regent's Park, London NW1 4RG, UK. Tel: +44 (0) 207724 5629. Fax: +44 (0) 2077235333. E-mail: denise@ffprhc.org.uk.Website: www.ffprhc.org.uk 